\title{
Proceeding
}

Supplementary Issue: Winter Conferences of Sports Science. Costa Blanca Sports Science Events, 24 April 2020. Alicante, Spain.

\section{Physical education of students with poor health}

\author{
TATIANA SHUTOVA, TATIANA VYSOTSKAYA , SVETLANA BOCHKAREVA, IGOR BODROV \\ Department of Physical Education, Plekhanov Russian University of Economics, Moscow, Russia
}

\begin{abstract}
Purpose: improving the performance of students with weak health by the means of fitness based on unit, person-centred, and systematic approaches. Materials and methods: students with weak health took part in the research ( $n=460$, age $18.0 \pm 0.82$ years). The experiment lasted for 9 months. With students of the control group (N1, $n=230$ in which 150 are girls and 80 are boys) traditional lessons were held in accordance with the current programme of physical education. For the experimental group (N2, $n=230$ in which 150 are girls and 80 are boys) blocks (module) in athletic gymnastics, water fitness, and aerobics were created with detailed competence. Electronic educational resources with video sets of special exercises were made and put into practice taking into account the underlying medical condition. Each unit contains goals and ways of achieving them. Person-centred approach included measuring physiological parameters. The systematic approach consisted of the organising of process of physical education with systematic monitoring of the functional state of the body. Results: by monitoring physical fitness by exercise testing, it was found out that all research subjects had improved their results. However, students in group N2 had achieved much higher figures than students in group N1. The noticeable increase in static, strength and coordination endurance was noted. Conclusion: the research has proven the efficiency of improving the process of physical education for students with weak health based on unit, personally oriented and systematic approaches.

Keywords: Educational approaches; Functional state of the body; Physical fitness; Monitoring of physical activity; Electronic educational resources.

\section{Cite this article as:}

Shutova, T., Vysotskaya, T., Bochkareva, S., \& Bodrov, I. (2020). Physical education of students with poor health. Journal of Human Sport and Exercise, 15(2proc), S177-S188. doi:https://doi.org/10.14198/jhse.2020.15.Proc2.08
\end{abstract}

Corresponding author. Department of Physical Education, Plekhanov Russian University of Economics, Moscow, Russia. https://orcid.org/0000-0002-2430-034

E-mail: golubnichaya2010@yandex.ru

Supplementary Issue: Winter Conferences of Sports Science. Costa Blanca Sports Science Events, 24 April 2020. Alicante, Spain.

JOURNAL OF HUMAN SPORT \& EXERCISE ISSN 1988-5202

(c) Faculty of Education. University of Alicante

doi:10.14198/jhse.2020.15.Proc2.08 


\section{INTRODUCTION}

In the recent years, a decent number of academic works concerning the realisation of physical education of students with weak health were created (Kondakov et al., 2016b; Skurikhina et al., 2016; Gorelov et al., 2013; Stepanova et al., 2015; Bogoeva, 2011; Zykov, 2012; Smirnova, 2006; Lyashenko, 2013; Bartnovskaya et al., 2014). According to the research data, $25-45 \%$ of students in Russia have health problems. Experts (Rumba, 2011; Kondakov, 2013; Ovsyannikova, 2015) state that the number of students who suffer from various physical development problems and have chronic illnesses have increased to $35-45 \%$. The main reason of cardiovascular diseases at the student age is the decline in physical activity. It is followed with decrease of heart size, decline in stroke volume and minute blood volume, and increased pulse rate, decreased mass of circulating blood (Rumba, 2011). Ministry of Health of Russian Federation provides data which shows that, among many various diseases of students, the most common are cardiovascular diseases (30-60\%). The next most common are musculoskeletal system disorders (25-40\%), ophthalmological diseases (13-25\%), diseases of the respiratory system etc.

Students of Plekhanov Russian University of Economics (Russia, Moscow), where the experiment was based, are, as a rule, the future workers in intellectual labour. Every year, scientific-and-technological advance increases the number of people performing intellectual labour. One of the defining features of intellectual labour is high tension of central nervous system (Nuzhdina \& Sineva, 2008; Maksimov \& Ivanova, 2011; Khimich, 2012; Bobko, 2007). As a result of the increase in the amount if intellectual labour, the time people spend on physical activity has declined dramatically. High nervous tension accompanied by low physical activity has quite a negative impact on a person's health, which means the same impact on the efficiency of his life and work performance. (Nuzhdina \& Sineva, 2008).

Intellectual labour is often specific in its influence on the human body. (Bukhtiyarov \& Matiukhin, 2014; Reznikov \& Churin, 2016). For intellectual labour workers, the most typical working position is sitting at the table or in front of the computer. In this, as a rule, bent position with the head put forward, the blood is distributed to organs and tissue unevenly. The legs, bent in hip and knee joints, don't experience even natural physical activity for long periods of time. Many muscle groups are constantly in the state of static tension, especially head, neck, shoulder girdle, and body muscles. Consequently, problems in brain sustenance, and engorgements in the abdomen, pelvic cavity, legs and arms may appear. Moreover, working at the office desk with paper documents or in front of the screen, a person has to look at one object for a long time. This causes the exhaustion of motor muscles in the eyes. In the works of physiologists of labour, it is noted that possible dizziness for many people who perform intellectual labour are the result of low training of the vestibular system, which is the consequence of prolonged putting the head forward without moving (Kapustina, Yushkova \& Matyukhin, 2018; Plekhanov, 2018). Hypokinesia worsens the state of the cardiovascular system. As it is commonly known, the brain needs significantly more oxygen to function than other organs. The state of heart and blood vessels is especially essential for intellectual labour workers. (Nuzhdina \& Sineva, 2008; Maksimov \& Ivanova, 2011).

Therefore, development of efficient approaches to improvement of physical education for students with weak health who are future workers of intellectual labour is important today.

Students with weak health are unable to learn the physical education programme that is typical for all students, and their lessons are based on special teaching methods. (Senter, Appelle \& Behera, 2013; Titov, 2013; Kashmina, 2012; Bogoeva, 2011; Zykov, 2012; Smirnova, 2006; Lyashenko, 2013; Bartnovskaya et al., 2014). In the system of higher education of Russian Federation, these students are considered a part of 
the special medical group. One of the most difficult problems in the organisation of process of physical education is that many students who have similar health disorders have quite significant differences in the functional state of their bodies and in the level of their physical ability (Adyrkhaev, 2016; Leo \& Goodwin, 2016; Kotelevskiy, 2016).

The current situation is made worse by the lack of curricular and extra-curricular physical activities which meet the interests of students. Scientific research on improving physical education of students with weak health found out their preferences concerning the types of fitness-based physical activity (Stepanova et al., 2015; Vengerova et al., 2018; Egorycheva, 2014; Ponyrko, 2013). Along with this, the lack of health-improving fitness programmes was educed (Shutova et al., 2018).

\section{MATERIAL AND METHODS}

\section{Participants}

Students with weak health took part in the research ( $n=460$, age $18.0 \pm 0.82$ years). Students were divided into two equal groups: the control group (N1) and the experimental group (N2), with 150 girls and 80 boys in each group.

The experiment lasted for 9 months and was held in Plekhanov Russian University of Economics (Russia, Moscow). Each group of students with weak health took lessons in physical education 2 times a week, each lesson being 90 minutes long. With students in group N1, traditional lessons were held in accordance with the current physical education programme. Classes included walking, running, general development exercises, games, and monitoring of physical fitness for basic physical qualities.

The improvement of physical education in group N2 is based on modular, personality-oriented and systematic approaches. Blocks (module) were created taking in account the focus on development of professionally important physical qualities and the preferences of students: in athletic gymnastics, water fitness, and aerobics. Each block (module) lasted for three months. The blocks (module) included detailed competence and special exercises. Each lesson consisted of general exercised and personalised sets of exercises taking in account the underlying medical condition. In order to achieve this, with the help of students, electronic educational resources which made it possible to organise autonomous learning during curricular and extracurricular classes were made and put into practice (Bochkareva et al., 2018a).

Person-centred approach included measuring the physiological parameters and the level of physical fitness before and at the end of the experiment. The resting blood pressure and heart rate parameters were measured by participants at home, and the results were fixed in their self-assessment journals. The lung capacity was measured with a portable spirometer during lessons. The response to the load of the cardiovascular system was evaluated using a sample with squats. The squat test is one of the simplest tests. Before taking the test, the participants rest while standing without moving for 3 minutes, after which the heart rate is measured for 1 minute. Then perform 20 deep squats for 30 seconds from the initial position of the leg at shoulder width, hands along the body. When squatting, the hands are brought forward, and when straightening, they are returned to the original position. After performing squats, the heart rate is calculated for one minute. The evaluation determines the rate of heart rate increase after exercise as a percentage.

The increase in the heart rate:

- Up to $20 \%$ means an excellent circulatory response to physical exercise;

- From 21 to 40\% - good response; 
- From 41 to $65 \%$ - acceptable response;

- From 66 to $75 \%$ - poor response;

- From $76 \%$ and higher - very poor response.

For the assessment of static, strength and coordination endurance and monitoring their changes, additional exercise tests on the base of fitness were added: plank position, squats with a body bar, and throwing a stuffed ball (Table 1).

Table 1. Assessment of physical fitness according to additional exercise tests based on the means of fitness.

\begin{tabular}{|c|c|c|c|}
\hline Type of exercise & Mark & Boys & Girls \\
\hline Plank position (sec) & 5 & 90 & 60 \\
\hline \multirow[t]{4}{*}{ Assessment of static endurance. } & 4 & 70 & 50 \\
\hline & 3 & 50 & 40 \\
\hline & 2 & 40 & 30 \\
\hline & 1 & 30 & 20 \\
\hline Squats with a body bar (girls $3 \mathrm{~kg}$; boys $5 \mathrm{~kg}$, number) & 5 & 22 & 20 \\
\hline \multirow[t]{4}{*}{ Assessment of strength endurance. } & 4 & 19 & 17 \\
\hline & 3 & 17 & 15 \\
\hline & 2 & 15 & 13 \\
\hline & 1 & 12 & 10 \\
\hline Throwing a stuffed ball (a $2 \mathrm{~kg}$ ball, the number of & 5 & 10 & 10 \\
\hline hitting the $50^{\star} 50 \mathrm{~cm}$ target on the floor, distance from & 4 & 8 & 8 \\
\hline the target is $5 \mathrm{~m}$ for boys and $4 \mathrm{~m}$ for girls). & 3 & 6 & 6 \\
\hline \multirow[t]{2}{*}{ Assessment of strength and coordination endurance. } & 2 & 4 & 4 \\
\hline & 1 & 2 & 2 \\
\hline
\end{tabular}

Autonomous physical activity for students in N2 group included prolonged walking. The number of steps made during the day was counted using fitness bands. The results were recorded daily in the self-assessment journals.

The systematic approach consisted of the organisation of process of physical education with systematic monitoring of functional status and physical fitness of the body.

\section{Statistical analysis}

To find out the significance of the results of the experiment the data was processed using the methods of mathematical statistics (Ivanov, 1990). The method of finding the significance of differences between average group results (the arithmetic mean, standard deviation, standard errors of the arithmetic mean) was applied with the usage of Student's t-test. The differences were considered significant with the level of significance $p$ $<.05$. Statistical processing of the results was performed using the standard software package Microsoft Excel 2007.

\section{RESULTS}

Based on the test results, no significant differences in physiological parameters and physical fitness between students in groups N1 and N2 were found at the beginning of the experiment. It was learned that before the experiment, students in N1 and N2 had low lung capacity for girls (N1-1658 \pm 117.4 ; N2-1663 $\pm 115.8 \mathrm{ml}$ ) and boys (N1-3494 $\pm 95.59 ; \mathrm{N} 2-3481 \pm 97.23 \mathrm{ml})$. The resting heart rate parameters were on the edge of 
normal for girls (N1-84.33 \pm 4.51 ; N2-83.3 \pm 5.25 ) and boys (N1-81.56 \pm 1.95 ; N2-81.55 \pm 2.04 ). The blood pressure parameters weren't very different from normal, both for girls (N1-117.1/77.1 $\pm 3.37 / 4.37$; N2$118.7 / 76.6 \pm 3.34 / 5.13)$ and boys $(123 / 82.1 \pm 4.3 / 5.32 ; 123.2 / 82.4 \pm 3.82 / 4.96)$. The circulatory reaction to physical exercise was acceptable, but closer to the edge of poor (girls N1-63.35 \pm 15.12 and N2-63.27 \pm 14.8; boys N1-63.6 \pm 11.7 and N2-63.9 \pm 11.23 ). Low levels of static endurance (girls N1-47.1 \pm 6.86 and $\mathrm{N} 2-47.9 \pm 6.98$; boys N1-71.5 \pm 0.71 and N2-71.38 \pm 0.83 ), strength (girls N1-6.87 \pm 1.46 and N2-6.89 \pm 1.38; boys N1-7.25 \pm 0.83 and N2-7.33 \pm 1.08 ) and coordination endurance (girls N1-5.59 \pm 1.83 and N2$5.76 \pm 1.76$; boys N1-6.36 \pm 2.33 and N2-6.4 \pm 1.96 ) were recorded.

At the end of the experiment all students demonstrated an improvement in the functional status and the physiological parameters. For example, the lung capacity parameter for girls in $\mathrm{N} 1$ has increased by $6 \%$, and for girls in $\mathrm{N} 2$ it has increased by $18 \%(\mathrm{p}<.05)$. For boys in $\mathrm{N} 1$ the lung capacity has increased by $1.25 \%$, and for boys in $\mathrm{N} 2$ it has increased by $8.5 \%(\mathrm{p}<.05)$. The circulatory reaction to physical activity hasn't changed significantly for group N1 (girls and boys). In group N2, the parameters for girls and boys have increased respectively by $48 \%$ and $47 \%(p<.05)$. The resting heart rate has decreased by $2.6 \%$ for girls in $\mathrm{N} 1$, for girls in $\mathrm{N} 2$ it has decreased by $1.6 \%$. For boys in $\mathrm{N} 1$ the parameters haven't changed significantly, for boys in N2, they have decreased by $4.5 \%$. The blood pressure parameters for both boys and girls stayed the same throughout the experiment. The results for heart rate and blood pressure haven't passed the significance test (Table 2).

Table 2. The parameters of functional status of students with weak health at the end of the experiment.

\begin{tabular}{|c|c|c|c|c|c|}
\hline \multirow{2}{*}{ Parameter } & \multirow{2}{*}{ Sex } & Control group (N1) & Experimental group (N2) & \multirow{2}{*}{$t$} & \multirow{2}{*}{$p$} \\
\hline & & $\mathrm{m} 1 \pm \mathrm{m} 1$ & $m 2 \pm m 2$ & & \\
\hline \multirow{2}{*}{$\mathrm{ABP}(\mathrm{mm} \mathrm{Hg})$} & $\mathrm{F}$ & $118.3 / 77.5 \pm 1.25 / 3.7$ & $119.7 / 78.3 \pm 1.11 / 2.3$ & $1.16 / 0.18$ & $p>.05 / p>.05$ \\
\hline & M & $121.2 / 81.2 \pm 1.8 / 5.75$ & $120.7 / 80.1 \pm 2.0 / 4.76$ & $0.18 / 0.148$ & $p>.05 / p>.05$ \\
\hline \multirow{2}{*}{ LC (ml) } & $\mathrm{F}$ & $1767 \pm 94.6$ & $2043 \pm 56.22$ & 2.5 & $p<.05$ \\
\hline & $M$ & $3538 \pm 74.42$ & $3806 \pm 95.59$ & 2.21 & $p<.05$ \\
\hline \multirow{2}{*}{ Resting CR (bpm) } & $\mathrm{F}$ & $82.17 \pm 3.44$ & $81.91 \pm 2.88$ & 0.05 & $p>.05$ \\
\hline & $M$ & $81.55 \pm 2.04$ & $78 \pm 1.49$ & 1.42 & $p>.05$ \\
\hline \multirow{2}{*}{ Sit to stand test (\%) } & $\mathrm{F}$ & $63.27 \pm 6.8$ & $42.77 \pm 7.37$ & 2.04 & $p<.05$ \\
\hline & M & $65.9 \pm 7.23$ & $43.48 \pm 6.91$ & 2.41 & $p<.05$ \\
\hline
\end{tabular}

The level of static endurance has increased by $13.2 \%$ for girls in $\mathrm{N} 1$, and by $29 \%$ for girls in $\mathrm{N} 2(\mathrm{p}<.05)$. For boys in $\mathrm{N} 1$ it has increased by $26 \%$, and for boys in $\mathrm{N} 2$ it has increased by $34.2 \%$. The level of strength endurance has increased by $8 \%$ for girls in N1, and by $33 \%$ for girls in N2 ( $<<.05)$. For boys in N1 it has increased by $17 \%$, and for boys in $\mathrm{N} 2$ it has increased by $47 \%(\mathrm{p}<.05)$. The level of coordination endurance hasn't changed for girls in N1, and it has increased by $34 \%$ for girls in N2 $(p<.05)$. For boys in N1 it slightly decreased, and for boys in N2 it has increased by $30 \%(p<.05)$ (Table 3 ).

Table 3. The results of physical fitness after the experiment.

\begin{tabular}{|c|c|c|c|c|c|}
\hline Type of exercise & Sex & Control group (N1) & Experimental group (N2) & & $\mathbf{p}$ \\
\hline & sex & $\mathrm{m} 1 \pm \mathrm{m} 1$ & $\mathrm{~m} 2 \pm \mathrm{m} 2$ & l & $\frac{n_{1}}{b}$ \\
\hline \multirow{2}{*}{ Plank position (sec) } & $\mathrm{F}$ & $54.3 \pm 4.78$ & $67.2 \pm 2.01$ & 2.48 & $p<.5$ \\
\hline & M & 96.5 & 108.6 & 4.7 & $p<.05$ \\
\hline \multirow{2}{*}{ Squats (score) } & $\mathrm{F}$ & $7.43 \pm 1.09$ & $10.22 \pm 0.7$ & 2.15 & $p<.05$ \\
\hline & M & $8.75 \pm 0.83$ & $13.78 \pm 1.49$ & 2.958 & $p<.05$ \\
\hline \multirow{2}{*}{ Throwing a stuffed ball (number) } & $\mathrm{F}$ & $5.23 \pm 1.05$ & $8.84 \pm 0.7$ & 2.86 & $p<.05$ \\
\hline & M & $5.05 \pm 1.24$ & $9.12 \pm 1.43$ & 2.176 & $p<.05$ \\
\hline
\end{tabular}




\section{DISCUSSION}

The research can be viewed as an addition to a list of scientific studies (Bartnovskaya et al., 2014; Egorycheva, 2014; Skurikhina et al., 2016) concerning the improvement of physical education for students with weak health.

The submitted material has a right to state that physical lessons involving the means of fitness based on unit, person-centred, and systematic approaches have a positive influence on students. It is clear that N2 have shown better results in most studied parameters than N1. Taking into account the preferences of students and the characteristics of studying and intellectual labour, blocks (module) from the system of fitness, fitnesssets which take into account the underlying medical condition and the specifics of labour were designed. Additional exercise tests which allowed to assess the level of development of professionally important physical qualities: static, strength, and coordination endurance, were included. Throughout the entire experiment, the assessment of physiological parameters and physical fitness, as well as counting the number of steps walked every day had been taking place. With the help of students, electronic educational resources in the format of sets of special physical exercises were created and put into practice. All the following components influenced the formation of the competence of students. A significant increase in learning motivation and an improvement in self-assessment culture had been noted. In the work of Carr et al. (2018) similar results were found, and it was shown that the involvement of students in new activities increases their motivation. The way of teaching in question was studied and proved to be effective in education and can therefore be considered by physical education professors (Gillette, 2017).

In the researches of Rumba (2011), Kondakov (2013), Bartnovskaya et al. (2014) the techniques of applying the means of recreational physical education in lessons for students in special study group should be noted. There was a rational approach to planning the contents and the organisation of learning and training process for physical education in a university. It is necessary to remember that the majority of the researches are focused on increasing of the efficiency of the learning process only. In our research, an accent was made on increasing the amount of physical activity during the day. Autonomous physical activity of students included prolonged walking with the counting of the number of steps (fitness bracelet). As the result of the research, it was proved that the teacher's control of autonomous physical activity can be effectively performed using a fitness bracelet. It lets the teacher control the received activity during a necessary period of time and motivates the owner to be more active.

In the works of Ovsyannikova (2015), Titov (2013) methods of using different types of recreational gymnastics in the process of physical education are demonstrated, but only for female students. However, the material and technical facilities and the organisation of the learning process in universities usually don't provide the possibility of forming study groups based on gender and physical ability. The method offered by the authors of this article allows to put girls and boys with different levels of physical fitness in one group.

The study of ways of correction of body posture for female university students by the means of recreational gymnastics (Ponyrko, 2013) is of interest. A sequence of dynamic and statodynamic exercises was explored with the aim of frontal posture correction. Bogoeva (2011) developed a process of physical education for students in the special medical group with cardiovascular system disorders with the application of respiratory exercises. Let's note that the percentage of students with various health disorders varies greatly. Therefore, grouping the students based on medical entity is difficult in the process of physical education in universities. The advantage of the method described by the authors of this article is in the ability to use it in physical education for students with weak health without grouping them based on their type of health disorder. 
In the work of Kh. M. Lyashenko (2013), a differentiated approach to physical education for students in the special medical group is described, but only for students with cardiovascular diseases, especially for those with unstable arterial blood pressure. The experimental programme of physical education is characterised by:

- A higher amount of physical activity of aerobic type;

- Its gradual increase;

- Exercises performed on the treadmill or the ergometric bicycle with background music;

- Increase in the amount of exercises aimed at the development of strength endurance of the muscles of the shoulder girdle and the upper limbs;

- Increase in the amount of exercises aimed at the development of coordination skills;

- Inclusion of autogenic training at the end of the lesson.

The increase in the amount of exercises aimed at the development of strength endurance only for the muscles of the shoulder girdle and the upper limbs can be discussed. In the experiment described in this article, exercises with integrated effect are suggested.

In the work of Zykov (2012) about adaptive physical education in accordance with the type of adaptation to physical exercise, a new method is suggested. It is based on differentiated and personalised usage of ways and methods of lesson teaching. A positive influence of the programme on the functional and intellectual performance and physical fitness was demonstrated. Unit, person-centred and systematic approaches which were used in the experiment correspond well with the specific principles of adaptive physical education. Our research also includes the teacher's control over the autonomous physical activity of students with various health disorders.

The received data is interesting because it allows objective assessment of improving of physical education for students with weak health by the means of fitness based on unit, person-centred, and systematic approaches.

\section{CONCLUSION}

The research allowed to ensure a positive dynamic in the functional state of the students and in the results of the exercise tests based on fitness. Significant differences were found in the level of physical fitness, the lung capacity parameters, and the circulatory reaction to physical exercise. The unit approach optimised the applied means of physical education on the base of artistic athletic gymnastics, water fitness and aerobics. For each unit, goals and ways to achieve them were set. Electronic educational resources with video sets of special exercises taking in account the types of health disorders, personal level functional status and physical fitness were created at experimentally tested. Person-centred approach led to the increase of physical activity of the students throughout the day, and the method of step counting ensured it. The systematic approach ensured an optimal organisation and recreational character of the whole process of physical education.

\section{CONFLICT OF INTEREST}

Authors state that there is no conflict of interest. 


\section{REFERENCES}

Akelaitis, A., \& Malinauskas, R. (2016). Education of Social Skills among Senior High School Age Students in Physical Education Classes. European Journal of Contemporary Education, 18 (4), 381 389. https://doi.org/10.13187/ejced.2016.18.381

Adyrkhaev, S.G. (2016). Modern technology of physical education of disabled students in conditions of inclusive education. Pedagogics, Psychology, Medical-biological Problems of Physical Training and Sports, 20 (1), 4-12. https://doi.org/10.15561/18189172.2016.0101

Bartnovskaya, L.A., Minchenkov, K.A., Kravchenko, V.M., Ponomarev, V.V., \& Doroshenko, S.A. (2014). Health-Improving-applied technology of physical education of students of special medical group of high school. Physical Culture: Education, Training, 6, 62-64.

Bendíková, E., \& Nemček, D. (2017a). Attitudes and Preferences of Children Living in Orphanage Towards Physical Education Lessons. European Journal of Contemporary Education, 6 (4), 664673. https://doi.org/10.13187/ejced.2017.4.664

Bendíková, E., \& Beáta Dobay, B. (2017b). Physical and Sport Education as a Tool for Development of a Positive Attitude Toward Health and Physical Activity in Adulthood. European Journal of Contemporary Education, 6 (1), 14-21. https://doi.org/10.13187/ejced.2017.1.14

Bendíková, E. (2016). Curricular Transformation of Education in the Field of Physical and Sport Education in Slovakia. European Journal of Contemporary Education, 18 (4), 410-417. https://doi.org/10.13187/ejced.2016.18.410

Bobko, N.A. (2007). The effect of stress on the work of the cardiovascular system of operators of preferredly mental work at different days of day and working week. Human Physiology, 3(33), 55-62.

Bogoeva, M.D. (2011). The Construction of the process of physical education of students of special medical group with disabilities of the cardiovascular system (dissertation). Saint-Petersburg: Lesgaft national state University of physical culture, sports and tourism [in Russia].

Bochkareva, S.I., Vysotskaya, T.P., Golubnichiy, S.P., Kopylova, N.E., \& Rostevanov, A.G. (2018a). Online learning resource design and employment in academic physical education. Teoriya i Praktika Fizicheskoy Kultury, 6, 26.

Bochkareva, S.I., Buyanova, T.V., Vysotskaya, T.P., \& Golubnichiy, S.P. (2018b). Online education resources applend in academic physical education process. Teoriya i Praktika Fizicheskoy Kultury, $3,15$.

Bukhtiyarov, I.V., \& Matiukhin, V.V. (2014). Physiology of labour: modern theoretical and scientificpractical aspects. Russian Journal of Physiology, 10, 1118-1129.

Carr, W., Timson, B., \& Volberding, J. (2018). Athletic Training Student Communication - What They Need to Talk About. Athletic Training Education Journal, 13(2), 175-184. https://doi.org/10.4085/1302175

Druz, V.A., lermakov, S.S., Nosko, M.O., Shesterova, L.Ye., \& Novitskaya, N.A. (2017). The problems of students' physical training individualization. Pedagogics, Psychology, Medical-biological Problems of Physical Training and Sports, 21(2), 4-12. https://doi.org/10.15561/18189172.2017.0201

Drogomeretsky, V.V., Kopeikina, E.N., Kondakov, V.L., \& lermakov, S.S. (2017). Adaptation of Ruffier's test for assessment of heart workability of students with health problems. Pedagogics, Psychology, Medical-biological Problems of Physical Training and Sports, 21 (1), 4-10. https://doi.org/10.15561/18189172.2017.0101

Divinskaya, A. E. (2013). Differentiated physical education of girls of 15-16 years of the special medical group with vegetative violations (dissertation). Volgograd: Volgograd Academy of physical culture [in Russia]. 
David, M., Williams, A. Charles Matthews, B., Candace Rutt, C., Melissa A. Napolitano, \& A. and Bess H. Marcusa (2008). Interventions to Increase Walking Behavior. Med Sci Sports Exerc. 40(7), 567573. https://doi.org/10.1249/MSS.0b013e31817c7006

Egorycheva, E.V. (2014). Technology of application of means of improving physical culture on occupations with students of special educational office (dissertation). Moscow: Moscow city pedagogical University [in Russia].

Esculier, J.F, Bouyer, L.J, \& Roy, J.S. (2016). The Effects of a Multimodal Rehabilitation Program on Symptoms and Ground-Reaction Forces in Runners With Patellofemoral Pain Syndrome. Journal of Sport Rehabilitation, 25(1), 23-30. https://doi.org/10.1123/jsr.2014-0245

Gillette Cordial, M. (2017). Consideration of Problem-Based Learning in Athletic Training Education. Athletic Training Education Journal, 12(3), 195-201. https://doi.org/10.4085/1203195

Goodwin, D., \& Howe, P.D. (2016). Framing Cross-Cultural Ethical Practice in Adaptive Physical Activity. Quest, 68(1), 43-54. https://doi.org/10.1080/00336297.2015.1117501

Gorelov, A.A., Kondakov, V.L., \& Belikova, Zh.A. (2013). About necessity of use of Hatha Yoga exercises for correction of deformation of students' spine of special medical groups with violations of posture. Physical Education of Students, 17(2), 35-44. https://doi.org/10.6084/m9.figshare.156378

Hands, B., Parker, H., Larkin, D., Cantell, M., \& Rose, E. (2016). Male and Female Differences in Health Benefits Derived from Physical Activity: Implications for Exercise Prescription. J Womens Health, Issues Care, 5, 4. https://doi.org/10.4172/2325-9795.1000238

Ivashchenko, O.V., \& Kapkan, O.O. (2016). Informative pedagogic control indicators of 14-15 years' age girls' motor fitness. Pedagogics, Psychology, Medical-biological Problems of Physical Training and Sports, 20 (6), 18-25. https://doi.org/10.15561/18189172.2016.0603

Ivanov, V.S. (1990). Fundamentals of mathematical statistics. Moscow: Physical education and sport [in Russia].

Kapustina, A.V., Yushkova, O.I., \& Matyukhin, V.V. (2018). Psycho-physiologic features of resistance to stress in some types of mental work. Occupational Health and Industrial Ecology. 1, 12-18. https://doi.org/10.31089/1026-9428-2018-1-12-18

Karas, T.Yu. (2006). Methodology of improvement of students of preparatory medical group of institutions of secondary professional education with use of means of navigation (dissertation). Khabarovsk: Far Eastern State Academy of physical culture [in Russia].

Kashmina, E.O. (2012). The Differentiated technique of physical education of students of special medical group on the basis of the account of a season of year (dissertation). Tula: Tula state University [in Russia].

Khimich, I.J. (2012). Physical exercise as a means of increasing resistance to the nervous-emotional stress of universities students. Physical Education of Students, 6, 123-127. https://doi.org/10.6084/m9.figshare.96603

Kondakov, V.L. (2013). System mechanisms of construction of sports and recreation technologies in the educational space of modern high school (dissertation). Saint-Petersburg: Belgorod state national research University [in Russia].

Kondakov, V.L, Kopeikina, E.N., \& Usatov, A.N. (2016). On purposefulness of application of physical culture-health related technology for prophylaxis of students' respiratory system disorders. Physical Education of Students, 20(2), 4-12. https://doi.org/10.15561/20755279.2016.0201

Kopeikina, E.N., Drogomeretsky, V.V., Kondakov, V.L., Kovaleva, M.V., \& lermakov, S.S. (2016). Modification of Harvard step-test for assessment of students with health problems functional potentials. Physical Education of Students, 4, 44-50. https://doi.org/10.15561/20755279.2016.0405

Kopylov, Yu.A., Jackowska, L.N., Kudryavtsev, M.D., Kuzmin, V.A., Tolstopyatov, I.A., \& lermakov, S.S. (2015). The concept of structure and content of health related trainings for higher educational 
establishments' students. Physical Education of Students, 5, 23-30. https://doi.org/10.15561/20755279.2015.0504

Kotelevskiy, V.I. (2016). Integrative technology of massage manipulations in physical rehabilitation of students with backbone pathology. Pedagogics, Psychology, Medical-biological Problems of Physical Training and Sports, 20(3), 31-40. https://doi.org/10.15561/18189172.2016.0305

Kozina, Z.L., lermakov, S.S., Kadutskaya, L.A., Sobyanin, F.I., Krzeminski, M., Sobko, I.N., \& Ryepko, O.A. (2016). Comparative characteristic of correlation between pulse subjective indicators of girl students' and school girls' reaction to physical load. Physical Education of Students, 4, 24-34. https://doi.org/10.15561/20755279.2016.0403

Kudryavtsev, M.D., Kopylov, Yu.A., Kuzmin, V.A., Ionova, O.M., \& Yermakova, T.S. (2016a). Personality oriented system of strengthening of students' physical, psychic and social-moral health. Physical Education of Students, 3, 58-64. https://doi.org/10.15561/20755279.2016.0306

Kudryavtsev, M.D., Kramida, I.E., lermakov, S.S., \& Osipov, A.Yu. (2016b). Development dynamic of healthy life style personality component in relatively healthy students. Physical Education of Students, 6, 26-33. https://doi.org/10.15561/20755279.2016.0603

Kuzmin, V.A., Kopylov, Y.A., Kudryavtsev, M.D., Tolstopyatov, I.A., Galimov, G.Y., \& Ionova, O.M. (2016). Formation of professionally important qualities of students with weakened motor fitness using a health related and sport-oriented training program. Physical Education and Sport, 16 (1), 136-145. https://doi.org/10.7752/jpes.2016.01023

Kuzmin, V.A., Kopylov, Yu.A., Kudryavtsev, M.D., Galimov, G.Y., \& lermakov, S.S. (2015). Substantiation of effectiveness of trainings on health related methodic for students with weakened motor fitness. Physical Education of Students, 6, 43-49. https://doi.org/10.15561/20755279.2015.0606

Kliziene, I., Klizas, S., Cizauskas, G., \& Sipaviciene, S. (2018). Effects of a 7-month Exercise Intervention Programme on the Psychosocial Adjustment and Decrease of Anxiety Among Adolescents. European Journal of Contemporary Education, 7(1), 127-136. https://doi.org/10.13187/ejced.2018.1.127

Lyashenko, H.M. (2013). Differentiated approach to the organization of physical education students of special medical group with cardiovascular disease (dissertation). Tula: Tula state University [in Russia].

Leo, J., \& Goodwin, D. (2016). Simulating Others' Realities: Insiders Reflct on Disability Simulations. Adapted Physical Activity Quarterly, 33(2), 156-161. https://doi.org/10.1123/apaq.2015-0031

Malinauskas, R. (2017). Enhancing of Self-Efficacy in Teacher Education Students. European Journal of Contemporary Education, 6(4), 732-738. https://doi.org/10.13187/ejced.2017.4.732

Maksimov, S.A., \& Ivanova, O.A. (2011). Social and hygienic aspects of labor adaptation of mental work employees. Hygiene and Sanitation, 2, 56-60.

Nagovitsyn, R.S., Chigovskaya-Nazarova, Y.A., Miroshnichenko, A.A., \& Senator, S.Y. (2018). The Realization of the System Programme "Health Saving Education" in the Pedagogical University. $\begin{array}{llll}\text { European Journal of } & \text { Contemporary } & \text { Education, } & 7(1), 149 .\end{array}$ https://doi.org/10.13187/ejced.2018.1.137

Nuzhdina, A.A., \& Sineva, E.L. (2008). Features of psychoemotional status and flow of arterial hypertension in mental labor workers. Medicine of Work and Industrial Ecology, 4, 8-12.

Ovsyannikova, M. A. (2015). Methods of using types of health-improving gymnastics in the process of physical education of students (dissertation). Malakhovka: Moscow state Academy of physical culture [in Russia].

Oleshev, N.In. (2015). Differentiated physical education of students on the basis of types of hemodynamics (dissertation). Tula: Northern (Arctic) Federal University named after Lomonosov [in Russia]. 
Osipov, A.Yu., Kudryavtsev, M.D., Kramida, I.E., lermakov, S.S., Kuzmin, V.A., \& Sidorov, LK. (2016). Modern methodic of power cardio training in students' physical education. Physical Education of Students, 6, 34-39. https://doi.org/10.15561/20755279.2016.0604

O'Dwyer, T., O'Shea, F., \& Wilson, F. (2016). Decreased health-related physical fitness in adults with ankylosing spondylitis: A cross-sectional controlled study. Physiotherapy (United Kingdom), 102(2), 202-209. https://doi.org/10.1016/.physio.2015.05.003

Ponyrko, E.A. (2013). Correction of posture in students by means of health-improving types of gymnastics (dissertation). Saint-Petersburg: Lesgaft national state University of physical culture, sports and tourism [in Russia].

Plekhanov, V.P. (2018). Assessing the risk of chronic overstra in in computer users, depending on age and length of service. Occupational Health and Industrial Ecology. 5, 58-61. https://doi.org/10.31089/1026-9428-2018-5-58-61

Radziminska, A., Weber-Rajek, M., Lulinska-Kuklik, E., Kazmierczak, U., \& Moska, W. (2016). Academic youth's health behavior. Physical Education of Students, 20(6), 55-62.

Reznikov, V.A., \& Churin, V.V. (2016). Estimation of the health of men and women in mental work. Journal of Restorative Medicine \& Rehabilitatuon, 4(74), 81-84.

Rozhkov, P.A. (2002). Development of physical culture and sports as priority direction of state social policy. Teoriia i praktika fizicheskoj kultury, 5, 20-22.

Rumba, O.G. (2011). System of pedagogical regulation of motor activity of students of special medical groups (dissertation). Saint-Petersburg: Russian state pedagogical University A. I. Herzen [in Russia].

Shutova, T.N., Vezenicyn, O.V., Vyprikov, D.V., \& Bodrov, I.M. (2015). The contents of athletic gymnastics and fitness in physical education students of special medical groups. Izvestia of the Tula state University. Physical culture and sport, 4, 70-76.

Skurikhina, N.V., Kudryavtsev, M.D., Kuzmin, V.A., \& lermakov, S.S. (2016). Fitness yoga as modern technology of special health groups' girl students' psycho-physical condition and psycho-social health strengthening. Physical Education of Students, 20(2), 24-31. https://doi.org/10.15561/20755279.2016.0204

Saidumova, I.S. (2008). Medico-social assessment of health status of medical students and ways of improvement of organization of medical care (dissertation). Voronezh: Voronezh state medical Academy. N. N. Burdenko of the Federal Agency for health and social development [in Russia].

Smirnova, O.L. (2006). Technology of application of types of gymnastics of the improving orientation in physical education of students of higher education institution (dissertation). Khabarovsk: Far Eastern State Academy of physical culture [in Russia].

Senter, C., Appelle, N., \& Behera, S.K. (2013). Prescribing exercise for women. Current Reviews in Musculoskeletal Medicine, 6(2), 164-72. https://doi.org/10.1007/s12178-013-9163-1

Stepanova, O.N., Vengerova, N.N., \& Pogodin, S.N. (2015). Conceptual Approach and Pedagogical Design Algorithm of Health and Fitness Classes. Theory and Practice of Physical Culture, 2, 20.

Titov, S.V. (2013). Physical education of students of special medical groups on the basis of complex use of strength (dissertation). Naberezhnye Chelny: Volga region state Academy of physical culture, sports and tourism [in Russia].

Tudor-Locke, C., Johnson, W., \& Katzmarzyk, P. (2009). Accelerometer-Determined Steps per Day in US Adults. Medicine Science in Sports Exercise, 41(7), 1384-1391. https://doi.org/10.1249/mss.0b013e318199885c

Vishnevsky, V.A. (2012). Method of multidimensional phase spaces in the management of the system of optimization of parameters of physiological and psychophysiological functions of schoolchildren of 
Ugra (dissertation). Surgut: Surgut state University of Khanty-Mansiysk Autonomous Okrug-Ugra [in Russia].

Vengerova, N.N., Piskun, O.E., Komissarov, E.N., \& Klyus, Y.A. (2018). Bioimpedance-based body composition rating tests for academic health physical education service design. Theory and Practice of Physical Culture, 9, 33-35.

Yakovlenko, D.V. (2009). Wellness physical education students with osteochondrosis of the spine based on the comprehensive corrective actions (dissertation). Velikie Luki: Velikolukskaya state Academy of physical culture and sports [in Russia].

Zykov, I.Yu. (2012). Adaptive physical education students of special medical groups based on the type of adaptation to physical stress (dissertation). Kirov: Vyatka state University for the Humanities [in Russia].

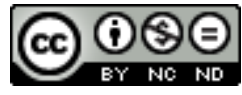

This work is licensed under a Attribution-NonCommercial-NoDerivatives 4.0 International (CC BY-NC-ND 4.0). 